\title{
High Prevalence of Adrenal Remnant Tissue in Patients Undergoing Bilateral Adrenalectomy for Cushing's Disease
}

Authors

Julian B. Wilson ${ }^{1}$, Mohan Zopey ${ }^{1}$, Jaimie Augustine ${ }^{1}$, Randolph Schaffer ${ }^{2}$, Manfred Chiang ${ }^{3}$, Theodore C. Friedman ${ }^{1}$

\author{
Affiliations \\ 1 Division of Endocrinology, Metabolism, and Molecular \\ Medicine, Charles R. Drew University of Medicine and \\ Science, Los Angeles, CA, USA \\ 2 Department of Surgery, Scripps Green Hospital, La Jolla, \\ CA, USA \\ 3 Brookfield Surgical Associates, Brookfield, WI, USA
}

Key words

Cushing's syndrome, remnant tissue, rest tissue, hypercortisolism, episodic, adrenalectomy

received $\quad 13.08 .2020$

accepted after revision $\quad 27.08 .2020$

published online 22.10 .2020

Bibliography

Horm Metab Res 2021; 53: 161-168

DOI 10.1055/a-1253-2854

ISSN 0018-5043

(C) 2020. Thieme. All rights reserved. Georg Thieme Verlag KG, Rüdigerstraße 14, 70469 Stuttgart, Germany

Correspondence

Theodore C. Friedman MD, PhD

Charles R. Drew University

Division of Endocrinology

1731 E. 120th. St.

90059 Los Angeles CA

USA

Tel.: + 13106685197 , Fax: + 13235639324

theodorefriedman@cdrewu.edu

\section{ABSTRACT}

Bilateral adrenalectomy (BLA) is a treatment option for patients with Cushing's Disease (CD) if transsphenoidal pituitary surgery fails or is not a therapeutic option. For most patients, BLA eliminates endogenous glucocorticoid and mineralocorticoid production, but for a small number of patients, endogenous secretion of adrenal hormones from adrenal tissue continues or recurs, leading to signs and symptoms of hypercortisolism. If adrenal tissue is confined to the adrenal bed, it is considered adrenal remnant tissue, while if it is outside the adrenal bed, it is considered adrenal rest tissue. We retrospectively evaluated morning serum cortisol, nighttime serum cortisol, nighttime salivary cortisol, and 24-h urine free cortisol on at least three occasions in 10 patients suspected of having endogenous cortisol production. Imaging of adrenal remnant tissue was also reviewed. Ten of 51 patients who underwent BLA during this time period had adrenal remnant/rest tissue marked by detectable endogenous glucocorticoid production; 9 of the 10 patients had signs and symptoms of hypercortisolism. Localization and treatment proved difficult. We conclude that the incidence of adrenal remnant/rest tissue in those undergoing BLA following unsuccessful pituitary surgery was $12 \%$ although there may have been a selection bias affecting this prevalence. The first indication of remnant tissue occurrence is a reduction in glucocorticoid replacement with symptoms of hypercortisolism. If this occurs, endogenous cortisol production should be tested for by cortisol measurements using a highly specific cortisol assay while the patient is taking dexamethasone or no glucocorticoid replacement. Endocrinologists need to monitor the development of both adrenal remnant tissue and Nelson's syndrome following BLA.

\section{Introduction}

Cushing's Disease [CD, pituitary-dependent Cushing's Syndrome (CS)] is characterized by increased cortisol secretion from the adrenal glands due to dysregulated secretion of ACTH by a corticotroph adenoma $[1,2]$. It is a relatively rare disease with an estimated annual incidence of 2-3 new cases per year per million [3] and primarily affects women between the ages of 20 to 50 years [4]. Signs and symptoms of hypercortisolism include central obesity with rapid weight gain, striae, hypertension, fatigue, and sleep disturbances [5]. The first line of treatment is transsphenoidal pituitary surgery, with remission rates ranging from $42 \%$ to $97 \%$ (me- dian $=78 \%$ ) when done by an experienced neurosurgeon [6]. If the surgery is unsuccessful or CD recurs, second-line therapeutic options include repeat transsphenoidal surgery, medical treatment, radiation, or bilateral adrenalectomy (BLA) [7]. BLA is usually used after transsphenoidal surgery has failed and the patient's hypercortisolism cannot be resolved with medical treatment. The disadvantages of BLA include the need for lifelong glucocorticoid and mineralocorticoid replacement and the risk of the subsequent development of adrenal crisis or Nelson's syndrome (pituitary corticotroph enlargement leading to hyperpigmentation following BLA) $[8,9]$. 
Endogenous cortisol production should cease following BLA, but there have been several case reports of hypercortisolism and CD recurrence following this procedure [10-15], although the rate of recurrence is poorly characterized in the literature. Cortisol production following complete BLA can come from one of two sources. One source, adrenal remnant tissue, is adrenal tissue (often microscopic) left behind following surgery that continues to secrete cortisol either immediately after surgery or following a period of regeneration often driven by high ACTH levels. The second potential source, adrenal rest tissue, is adrenal tissue that arises ectopically that can be from an accessory adrenal gland that are developmental anomalies that occur when a small fragment breaks off from the parent adrenal gland during intrauterine life, and usually atrophy with age $[16,17]$. ACTH controls adrenal gland development [18], regeneration [19], the differentiation of cells into a zona fasciculata phenotype that produces cortisol [20], and cortisol synthesis and secretion [1]. Consistent with this, the ability of adrenal remnant tissue, adrenal rest tissue, and accessory adrenal glands to grow and upregulate cortisol secretion under ACTH secretion following adrenal gland removal has been demonstrated in numerous animal and human studies [21-25].

The rate of adrenal remnant/rest tissue appears to be more common in congenital adrenal hyperplasia (CAH) [26], possibly due to the high ACTH associated with the condition. One early report by Kemink et al. [11] evaluated 37 CD patients who had BLA surgery performed between 1962 and 1988; many of the surgeries were performed before 1980 when BLA was the first-line treatment for CD. The authors found that 9 patients ( $24 \%$ ) continued having endogenous cortisol secretion and one patient (3\%) had a recurrence in the symptoms and signs of CS [11]. Later, in a review article on BLA outcomes following CS, Ritzel et al. [8] examined PubMed articles published between 1980 and 2012 and noted five studies (containing 236 patients in total) that reported residual cortisol secretion after an operation. From these studies, the authors concluded that accessory adrenal tissue or adrenal remnant tissue was found in $3-34 \%$ of patients and less than $2 \%$ had a relapse of CS [8]. However, another more recent report that examined 21 patients with BLA between 1970 and 2012 found a 14\% CS recurrence rate [27].

Due to the heretofore small number of cases of adrenal remnant/rest tissue in patients with CS, there have been few individual case studies and even fewer publications that characterize and compare the management of a group of patients. In 1972, Siegal et al. [13] described four patients who experienced a CS recurrence following BLA. Given that the management of CS, imaging techniques, and both surgical and medical treatment options have changed dramatically since this report was published, a more contemporary study is needed to provide guidance on the detection and management of this condition. This article describes the evaluation and treatment of 10 patients with CD who demonstrated adrenal remnant or rest tissue following BLA surgery, 9 of whom had recurrent hypercortisolism.

\section{Subjects and Methods}

The Institutional Review Board (IRB) of Charles R. Drew University of Medicine and Science deemed that retrospective review of the collected data was exempt from formal IRB review, in accordance with federal regulations (45CFR 46.101[b])

The biochemical evaluation for patients with CS consisted of multiple measurements of 24-h urinary free cortisol (UFC) and 17-hydroxycorticosteroids, and measurements of nighttime salivary and serum cortisol. Many of the patients were reported in our prior publications [28-30]. All patients had persistent hypercortisolemia despite one or more transphenoidal pituitary surgeries. All patients had complete BLAs performed laparoscopically through a retroperitoneal approach, which is associated with similar outcomes as a transperitoneal lateral approach [31,32], with 6 of the 10 patients having this procedure performed by MC. The other four patients were operated by surgeons with extensive experience with adrenal surgeries.

The 10 patients in this study were treated by the senior author (TCF) from 2006-2020. During this time, 51 patients seen by TCF underwent BLA. Six of these patients developed adrenal remnant tissue following surgery, thus the incidence or remnant/rest tissue following BLA can be estimated at $12 \%$ (6/51). These six patients are included in this study, and the remaining four patients in the study (P1, P4, P5, and P7) were referred to TCF after their adrenalectomy with subsequent suspicion of adrenal remnant tissue. The other 45 patients who underwent bilateral adrenalectomy were on stable, physiological glucocorticoid replacement and did not report symptoms of hypercortisolism.

We measured morning serum cortisol, nighttime serum cortisol, nighttime salivary cortisol, and 24-h UFC on at least three occasions for 10 patients suspected of having endogenous cortisol production. Patients who could safely refrain from glucocorticoid replacement (or were already off glucocorticoid replacement) for testing were told to do so. Patients at risk of developing adrenal insufficiency were given physiological dexamethasone replacement (0.5-1 mg per day, which does not cross-react with cortisol assay) to avoid adrenal insufficiency for $2-3$ days prior to and during testing for endogenous cortisol production. All hormones were measured by Esoterix Endocrinology (Calabasas Hills, CA, USA). Salivary, plasma, and UFC were measured by HPLC MSMS (high pressure liquid chromatography with tandem mass spectrometry detection) after solvent extraction. For 0800 plasma cortisol measurement, the $95 \%$ tolerance interval (normal range) as reported by Esoterix Endocrinology is $221-524 \mathrm{nmol} / \mathrm{l}$, with an assay sensitivity of $27.6 \mathrm{nmol} / \mathrm{I}$ [33]. The range of nighttime salivary is $0.3-2.5 \mathrm{nmol} / \mathrm{I}$ and the range of $24-\mathrm{h}$ UFC in women is $27.6-93.8 \mathrm{nmol} /$ day. There was no cross-reactivity in the cortisol assay with dexamethasone or fludrocortisone.

\section{Results}

\section{Surgical results}

The adrenals with capsules were removed en bloc and the pathology of all patients showed enlarged adrenal glands with focal nodular cortical hyperplasia. \$ Table 1 shows clinical data from 10 female patients who developed adrenal remnant or rest tissue following BLA. One patient had rest tissue in her ovary in addition to remnant tissue in her adrenal bed; the other nine patients had remnant tissue found or suspected in their adrenal beds. None of the 


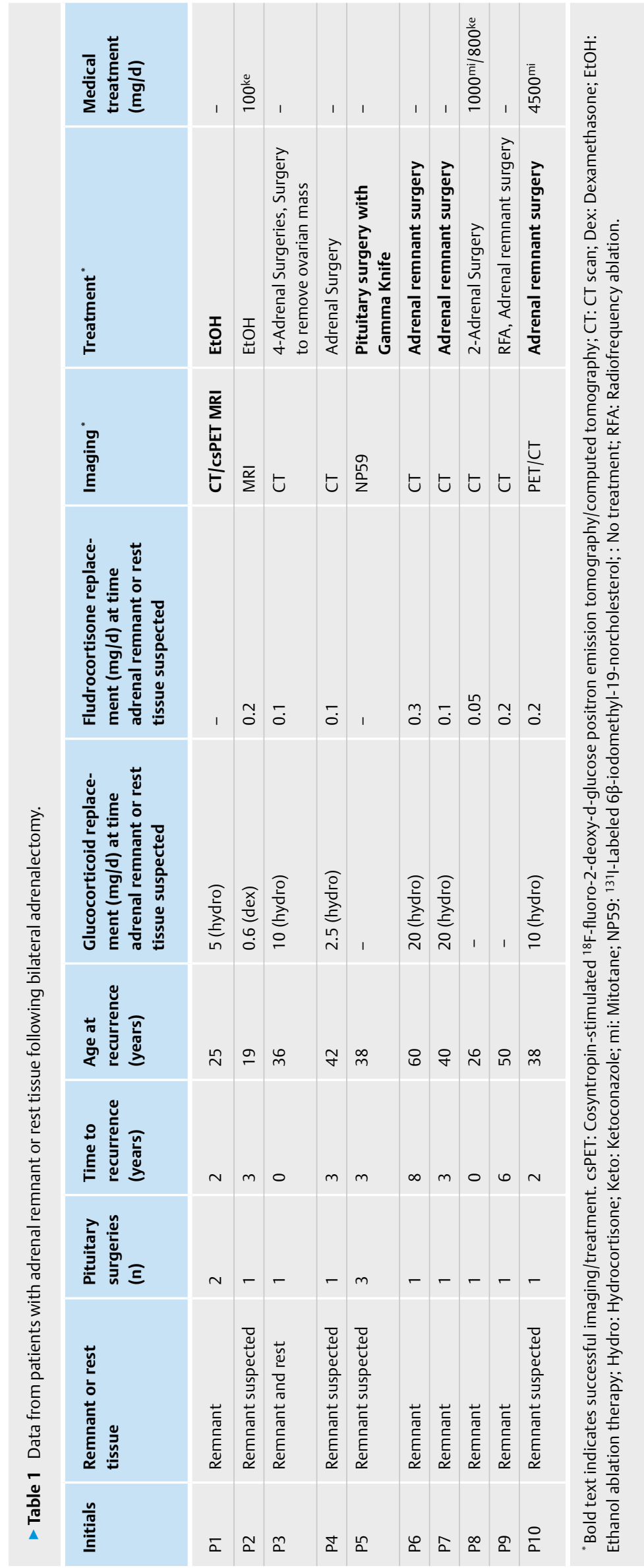


patients had accessory adrenal glands. Since these patients had complete BLAs, their endogenous cortisol secretion should have been undetectable when measured when on either dexamethasone or no cortisol replacement. However, following surgery the patients had detectable cortisol levels, confirming the presence of endogenous cortisol production, with 9 patients developing symptoms and signs of recurrent hypercortisolism.

\section{Hormonal replacement}

At the time recurrence was confirmed, only 3 patients (P6, P7, and P9) were taking physiologically appropriate levels of glucocorticoid replacement. The other patients had either greatly reduced or stopped replacement doses to minimize their hypercortisolism symptoms. This was a key sign that endogenous cortisol production was occurring. Three patients (P5, P8, and P9) were able to stop their glucocorticoid replacement and did not develop symptoms associated with adrenal insufficiency. $P 9$ did require full glucocorticoid replacement following adrenal remnant removal. In contrast, 8 patients were taking physiologically appropriate levels of mineralocorticoid replacement at the time of recurrence confirmation. This consisted of fludrocortisone replacement titrated to achieve a sitting plasma renin activity in the normal range, yielding daily dosing between $0.05 \mathrm{mg}$ and $0.3 \mathrm{mg}$. Serum potassium levels were normal in all patients. The remaining two patients did not require fludrocortisone replacement. In one patient (P5), adrenal remnant tissue was making sufficient amounts of both glucocorticoids and mineralocorticoids, which was balanced by prior pituitary surgery and radiation. She did not need exogenous glucocorticoid or mineralocorticoid replacement. Following adrenal remnant removal, patient P9 appeared cured of her endogenous cortisol production and required physiological glucocorticoid and mineralocorticoid replacement.

As shown in > Table 2, despite BLA surgery, all 10 patients had detectable cortisol measurements, with 9 out of 10 patients having detectable cortisol measurements in at least two different types of assessment. As can be seen in > Table 2, nighttime serum and salivary measurements were often much higher than morning levels, suggesting a dysregulation in cortisol secretion from the adrenal remnant tissue. This corresponded to several patients reporting symptoms of hypercortisolism at night, including insomnia, without symptoms of adrenal insufficiency in spite of subphysiological glucocorticoid replacement.

DHEAS levels, measured in patients who are either not taking DHEA or withheld DHEA for several days prior to testing, varied considerably. In six patients, serum DHEAS levels were below the detection limit $(0.27 \mu \mathrm{mol} / \mathrm{I})$, in two patients they were in the normal range $(<6.2 \mu \mathrm{mol} / \mathrm{I})$, in one patient they were elevated, and no measurement was performed for one patient.

\section{Adrenal remnant tissue imaging}

High-resolution CT scans was the primary means to localize adrenal remnant or rest tissue; possible adrenal tissue was localized in all 8 patients. The identified tissue was usually seen in the adrenal bed but was also found near the aorta, just behind the adrenal artery (P3) and in the posterior upper pancreas (P8). Although masses identified by $C T$ were removed from all patients, surgery directed at the lesions seen on imaging was only successful in three patients (P6, P7, and P9). All other surgeries yielded tissue of negative pathology that represented fat necrosis (P2, P3, and P4), benign lymph nodes (P8), or ganglionic neural tissue (P10) with continued endogenous cortisol secretion.

Both PET and MRI scans were used once, and the PET scan was not successful in localizing the adrenal remnant tissue. In one patient (P3), abdominal imaging showed an ovarian mass that was then removed. The pathology of the ovarian tissue did not show adrenal tissue. Some of the patient's hypercortisolism-related symptoms improved following surgery, but she still experienced endogenous cortisol secretion. Thus, it is likely she had both adrenal rest tissue (ovary) and remnant tissue (adrenal bed). Only one patient (P1) had adrenal remnant tissue identified using MRI, which

- Table 2 Detection of exogenous glucocorticoid secretion following bilateral adrenalectomy.

\begin{tabular}{|c|c|c|c|c|c|}
\hline Initials & $\begin{array}{l}\text { Glucocorticoid replacement at } \\
\text { time of testing }\end{array}$ & $\begin{array}{l}\text { Morning serum } \\
\text { cortisol (nmol/l) }\end{array}$ & $\begin{array}{l}\text { 24-h UFC } \\
\text { (nmol/d) }\end{array}$ & $\begin{array}{l}\text { Night time salivary } \\
\text { cortisol (nmol/I) }\end{array}$ & $\begin{array}{l}\text { Midnight serum } \\
\text { cortisol (nmol/l) }\end{array}$ \\
\hline P1 & Dexamethasone & BDL & BDL, 6.6 & 19.0 & BDL \\
\hline P2 & Dexamethasone & $91.0,386$ & & $5.2,19.0,2.6,4.1$ & \\
\hline P3 & Dexamethasone & 224 & & & $248,304,359$ \\
\hline P4 & Dexamethasone & $\begin{array}{l}91.0,80.0,66.2 \\
71.7,88.3\end{array}$ & $16.8,4.7$ & $18.2,5.0,4.7,3.0,1.6$ & \\
\hline P5 & Dexamethasone & $607,99.3,141,199$ & 497 & & \\
\hline P6 & No replacement & & 5.0 & $12.1,19.0$ & \\
\hline P7 & Dexamethasone & 2.8 & & $4.1,0.8,1.1,1.4$ & \\
\hline P8 & No replacement & & BDL & & 364,477 \\
\hline P9 & No replacement & & & 9.8 & \\
\hline P10 & Dexamethasone & $38.6,116,135,331$ & 16.0 & & \\
\hline
\end{tabular}



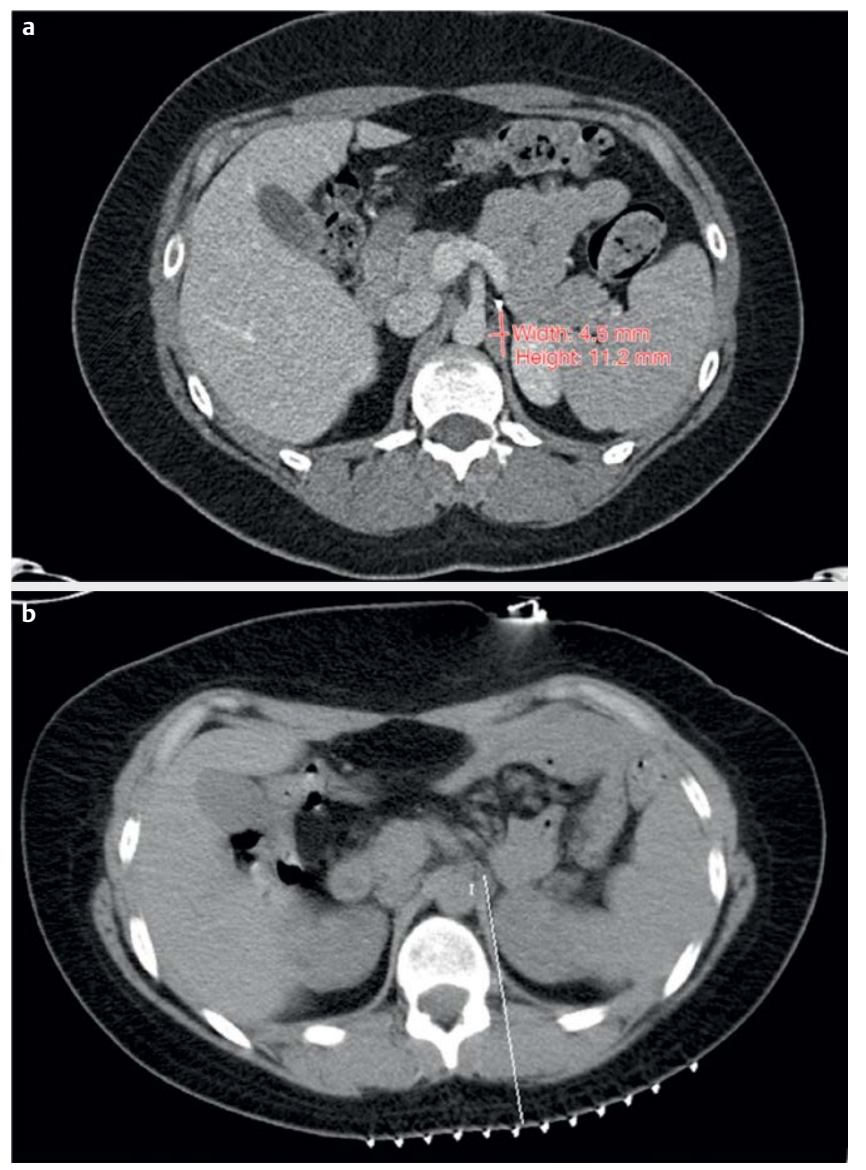

- Fig. 1 a CT with contrast of adrenal remnant tissue measuring $11.2 \mathrm{~mm}$ by $4.5 \mathrm{~mm}$. b CT posterior approach for ethanol ablation of residual adrenal tissue.

was successfully treated with ethanol ablation. CT-guided ethanol ablation (P1) and CT-guided radio frequency ablation (P9) were each used on one occasion, with only the ethanol ablation being successful [34].

- Figure 1a shows the CT scan of patient P1, showing adrenal remnant tissue measuring $11.2 \mathrm{~mm}$ by $4.5 \mathrm{~mm}$. - Figure $1 \mathbf{b}$ shows a posterior approach for ethanol ablation of the adrenal remnant tissue.

\section{Discussion}

\section{Adrenal remnant prevalence and comparison to literature}

In the present study, we characterized 10 patients who were found to have endogenous cortisol secretion following a BLA for CD that was not successfully treated with pituitary surgery. All patients had complete BLA performed laparoscopically via a retroperitoneal approach, but the development of adrenal remnant or rest tissue probably occurred independent of this surgical technique. Our $12 \%$ rate of adrenal remnant/rest tissue causing hypercortisolism was similar to the 3-34\% rate yielded by a literature review (5 studies, 236 patients) and the $2 \%$ rate who had a CS relapse, as reported by
Ritzel et al. [8] Our rate is in agreement with a report by Morris et al. [27] who found recurrence in 3 of 21 (14\%) patients who were treated with steroidogenesis inhibitors and BLA for their ACTH-dependent CS. Although their report was attributed to inexperience of the surgeon with the particular BLA surgical technique used (i.e., posterior retroperitoneoscopic adrenalectomy), the study obtained a similar rate of recurrence of endogenous cortisol production as seen in the present study.

\section{Patient characteristics}

The most challenging aspect in both the diagnosis and treatment of patients was the episodic and intermittent nature of cortisol secretion from adrenal remnant tissue. This is consistent with our series in 2010 in which we found that 65 of the 66 patients with CS had at least one normal test of cortisol status [35], a finding that was confirmed by others [36, 37]. Although 9 of 10 patients in our current series presented with symptoms and signs of hypercortisolism such as weight gain (truncal and generalized), anxiety with sleep disturbance, moon faces, tachycardia, buffalo hump (sometimes painful), and striae, their morning serum cortisol levels were often low and frequently below the measurable limit. Further complicating diagnosis was the finding that these patients frequently also exhibited symptoms of adrenal insufficiency such as morning/ daytime fatigue (all patients) and nausea with vomiting (P2, P3, P8, $\mathrm{P9}$, and P10). Repeated measurements of serum morning and nighttime cortisol, 24-h UFC, and nighttime salivary cortisol measurements showed inappropriately normal or elevated cortisol secretion. Many patients in this study had reversed circadian rhythm with relatively high nighttime cortisol levels and low levels in the morning. As ACTH secretion of the pituitary tumor may have been under regulation by dexamethasone, endogenous cortisol might have been suppressed when testing was done on dexamethasone. Thus, the detectable cortisol may have been higher if not on dexamethasone.

\section{Imaging characteristics}

Once the presence of endogenous cortisol secretion was confirmed, we used various imaging techniques to localize the cortisol-secreting tissue, with use often limited by availability or the patient's health insurance. CT scans have long been used in the imaging and diagnosis of adrenal causes of CS [38,39] and we used this imaging technique in 8 of the 10 patients to localize their remnant tissue; possible adrenal remnant lesions in the adrenal bed were found in 7 of 8 patients. Other imaging techniques reported for finding such tissue include cosyntropin-stimulated ${ }^{18} \mathrm{~F}$-fluoro2-deoxy-D-glucose PET/CT ( ${ }^{18} \mathrm{~F}$-FDG-PET/CT) and ${ }^{131} \mathrm{I}$-labeled $6 \beta$-iodomethyl-19-norcholesterol (NP59) scans. ${ }^{18} \mathrm{~F}$-FDG-PET/CT scans use radiolabeled glucose molecules as a marker for tissue that has increased levels of glycolysis. This technique is primarily used to detect malignancies $[40,41]$, but can also be used to detect metabolically active adrenal tissue [42]. In previous case reports, ${ }^{18}$ F-FDG-PET/CT successfully localized adrenal rest tissue in a patient with $\mathrm{CAH}$ [43] and in a patient with Nelson's syndrome with persistent hypercortisolism [44]. In the present study, in patient (P2), we used a ${ }^{18}$ F-FDG-PET/CT scan to visualize potential adrenal remnant tissue after it was clearly visualized on a CT scan. Her ${ }^{18}$ F-FDG-PET/CT scan gave only a faint signal at that location, sug- 
gesting that the tissue seen on CT scan probably was not remnant tissue, and destruction of this tissue via ethanol ablation would not relieve symptoms. NP59 scanning uses a radiolabeled cholesterol that is a precursor of cortisol and tracks its uptake in steroidogenic tissue $[45,46]$. Before it became unavailable in the United States, it was used in patient P5, but scanning was unable to localize any potential cortisol-producing tissue. New imaging modalities including Metomidate PET/CT [47] and [ ${ }^{68} \mathrm{Ga}$ ]-DOTATATE PET/CT [48] have the potential to localize adrenal remnant/rest tissues.

\section{Adrenal remnant treatment}

Adrenal remnant or rest tissue, if found, can be treated by a variety of procedures. Six patients underwent exploratory surgery in order to find and remove the aberrant tissue found on CT scan. However, in only two patients (P6 and P7) did this lead to a successful surgical outcome, with resolution of endogenous cortisol secretion and hypercortisolism symptoms and subsequent return to normal glucocorticoid replacement. For the other patients (P3, P4, and P8), aberrant tissue was removed, but adrenal tissue was not seen on pathology, of which the pathology usually showed fat tissue. Two patients (P1 and P5) did not need to undergo surgery to remove potential adrenal remnant or rest tissue, with patient $\mathrm{P} 1 \mathrm{hav}$ ing successful ethanol ablation and patient P5 having normal cortisol secretion due to her prior pituitary surgery/radiation.

As an alternative to exploratory surgery, other techniques can be used to eliminate pathological tissue. Ethanol ablation therapy is performed by placing several small (19-22 gauge) needles under the guidance of CT, real-time CT fluoroscopy or ultrasound, and injecting ethanol into the target tissue $[49,50]$. This causes protein denaturation leading to coagulative necrosis and thrombosis of small vessels. This procedure was successfully performed on one patient in this study (P1) [34] ( Fig. 1) but was unsuccessful in another patient (P2). Another technique is radiofrequency ablation [51], in which electrodes are placed inside the target tissue and heated with high intensity radio waves, which leads to tissue destruction in a manner analogous to ethanol ablation [52]. This procedure was previously done on both adrenal beds in a patient with CS [53] and was performed on one of the patients in this study (P9), leading to short-term resolution of hypercortisolism symptoms, which later recurred. Additionally, pituitary surgery or radiation can be used to decrease ACTH secretion, especially if a lesion is identified on pituitary imaging. All of our patients underwent periodic pituitary imaging with no lesions seen, so pituitary surgery or radiation were not performed.

While waiting to undergo surgery, or as an alternative to surgery, several drugs can be used to treat CS [54, 55]. Ketoconazole is a synthetic imidazole that was once widely used as an antifungal agent. Soon after its introduction, it was discovered that in addition to blocking fungal cytochrome P450 14 $\alpha$-demethylase (CYP51A1), ketoconazole blocks many human P450 enzymes to lower steroid production [56] and was found to be a human glucocorticoid receptors antagonist $[57,58]$. Patients using ketoconazole for CS typically need to take 400 to $1600 \mathrm{mg}$ daily for effective treatment [54, 59]. Mitotane (o, $p^{\prime}$-DDD; Lysodren) is another drug that can be used in the medical treatment of CS. In addition to blocking multiple cytochrome P450 enzymes to inhibit steroidogenesis, it is cytolytic and chronic administration can lead to adrenal atrophy [60], making it, in theory, an ideal drug to use with patients who have adrenal remnant or rest tissue. However, because of its side effects, especially severe nausea, mitotane is primarily used in the treatment of adrenal carcinomas [61], but doses up to $4 \mathrm{~g}$ per day have been used to treat CS [62]. Several patients in the current series tried mitotane, but could not tolerate it due to side effects.

\section{Limitations}

There are several limitations to this study, including the limitations inherent in a retrospective study and the heterogeneous cases that varied with clinical scenario. Patients underwent surgery by different surgeons. It is possible, but unlikely, that surgical expertise led to incomplete BLA with subsequent remnant formation. Although data were collected from all patients for morning serum cortisol, nighttime serum cortisol, nighttime salivary cortisol, and 24-h UFC, the tests were completed to varying degrees and had different positive values showing detectable cortisol levels that would have been more standardized had the study been done prospectively. NP-59 scanning, the test most likely to identify adrenal remnant tissue, is no longer available in the United States. Imaging techniques that could have detected the remnant tissue may not have been used due to lack of availability or insurance issues. There may be a selection bias since patients were referred to or treated by TCF accounting for a higher prevalence than would be found in the population. It is also possible that we underestimated the rate of adrenal remnant development as some patients with endogenous cortisol production may not have had symptoms of excess cortisol secretion and may not have sought medical attention. One of the cases was published in the September 2011 [63].

\section{Conclusion}

Our series showed adrenal remnant tissue occurring in about $12 \%$ of patients who had BLA. This compares to the $21 \%$ mean incidence of Nelson's syndrome following BLA in a review of 24 studies with 768 patients [8]. None of our patients who underwent BLA developed Nelson's syndrome. Thus, an examination for both adrenal remnant tissue development and Nelson's syndrome should occur following BLA.

The first indication of remnant tissue occurrence is a reduction in glucocorticoid replacement with symptoms of hypercortisolism. If this occurs, endogenous cortisol production should be tested for by cortisol measurements using a highly specific and sensitive assay while the patient is on dexamethasone or no glucocorticoid replacement. Localization of adrenal remnant tissue was found to be difficult, with a lack of specificity of imaging techniques such as high-resolution CT scans. If a lesion is found, it can be removed by surgery, ethanol ablation, or radiofrequency ablation, although the success of these procedures is limited. Our retrospective study should be followed up by a large prospective study from centers that perform a large volume of BLAs for patients with CD to determine adrenal remnant recurrence rates, optimization of localization techniques, and treatment modalities. 


\section{Funding Information}

TF received funding by the Accelerating Excellence in Translational Science (AXIS) grant \#U54MD007598, National Institute on Minority Health and Health Disparities grant \#S21MD000103, Diversity-Promoting Institution Drug Abuse Research Program (DIDARP) grant (R24DA017298) and California Tobacco-Related Disease Research Program (TRDRP) Grant 251P003 and 28CP-0040.

\section{Acknowledgments}

The authors thank Lynwood Lord of the CTSI Grants Submission Unit, UCLA Clinical and Translational Science Institute (CTSI), UCLA David Geffen School of Medicine for his critical review of the manuscript.

\section{Conflict of Interest}

The authors declare that they have no conflict of interest.

\section{References}

[1] Friedman TC. The adrenal gland. In: Benjamin IB, Griggs RC, Wing E], Fitz JG, Eds. Andreoli and Carpenter's Cecil Essentials of Medicine. 9th ed. Philadelphia: Saunders Elsevier; 2015: 642-651

[2] Newell-Price J, Bertagna X, Grossman AB et al. Cushing's syndrome. Lancet 2006; 367: 1605-1617

[3] Stewart PM, Newell-Price JDC. The Adrenal Cortex. In: Melmed S, Polonsky KS, Larsen PR, Kronenberg HM, Eds. Williams Textbook of Endocrinology. 13th edition. Philadelphia, PA: Elsevier; 2016: 489-555

[4] Sharma ST, Nieman LK, Feelders RA. Cushing's syndrome: Epidemiology and developments in disease management. Clin Epidemiol 2015; 7: 281-293

[5] Nieman LK, Biller BM, Findling JW et al. The diagnosis of Cushing's syndrome: An Endocrine Society Clinical Practice Guideline. J Clin Endocrinol Metab 2008; 93: 1526-1540

[6] Petersenn S, Beckers A, Ferone D et al. Therapy of endocrine disease: Outcomes in patients with Cushing's disease undergoing transsphenoidal surgery: Systematic review assessing criteria used to define remission and recurrence. Eur J Endocrinol 2015; 172: R227-R239

[7] Rizk A, Honegger J, Milian M et al. Treatment Options in Cushing's Disease. Clin Med Insights Oncol 2012; 6: 75-84

[8] Ritzel K, Beuschlein F, Mickisch A et al. Clinical review: Outcome of bilateral adrenalectomy in Cushing's syndrome: a systematic review. J Clin Endocrinol Metab 2013; 98: 3939-3948

[9] Reincke M, Ritzel K, Osswald A et al. A critical reappraisal of bilateral adrenalectomy for ACTH-dependent Cushing's syndrome. Eur ] Endocrinol 2015; 173: M23-M32

[10] Chaffee WR, Moses AM, Lloyd CW et al. Cushing's syndrome with accessory adrenocortical tissue. JAMA 1963; 186: 799-801

[11] Kemink L, Hermus A, Pieters $G$ et al. Residual adrenocortical function after bilateral adrenalectomy for pituitary-dependent Cushing's syndrome. J Clin Endocrinol Metab 1992; 75: 1211-1214

[12] Strauch GO, Vinnick L. Persistent Cushing's syndrome apparently cured by ectopic adrenalectomy. JAMA 1972; 221: 183-184

[13] Siegal AM, Kreisberg RA, Hershman JM et al. Recurrent Cushing's disease following total adrenalectomy. Arch Intern Med 1972; 129: 642-647
[14] Leibowitz ], Pertsemlidis D, Gabrilove J. Recurrent Cushing's syndrome due to recurrent adrenocortical tumor-fragmentation or tumor in ectopic adrenal tissue? J Clin Endocrinol Metab 1998; 83: 3786-3789

[15] Ayala AR, Basaria S, Udelsman R et al. Corticotropin-independent Cushing's syndrome caused by an ectopic adrenal adenoma. J Clin Endocrinol Metab 2000; 85: 2903-2906

[16] Schechter DC. Aberrant adrenal tissue. Ann Surg 1968; 167: 421-426

[17] Ben-Mordechay D, Ben-Shlush A, Raviv-Zilka L et al. Sonographic detection of accessory adrenal tissue in neonates. J Ultrasound Med 2016; 35: 959-963

[18] Kempná P, Flück CE. Adrenal gland development and defects. Best Pract Res Clin Endocrinol Metab 2008; 22: 77-93

[19] Nickerson PA, Brownie AC, Skelton F. An electron microscopic study of the regenerating adrenal gland during the development of adrenal regeneration hypertension. Am J Pathol 1969; 57: 335

[20] Kahri A. Histochemical and electron microscopic studies on the cells of the rat adrenal cortex in tissue culture. Acta Endocrinol 1966; 52: S8-S96

[21] Wiesel ]. Ueber Compensations-Hypertrophie der accessorischen Nebennieren bei der Ratte. Centr Physiol 1898; XII: 780

[22] Karakascheff KI. Weitere Beitrage zur pathologischen Anatomie der Nebennieren. Beitr Pathol 1906; 39: 373

[23] Chalmers R, Mashiter K, Joplin G. Residual adrenocortical function after bilateral "total" adrenalectomy for Cushing's disease. Lancet 1981; 318: 1196-1199

[24] Blichert-Toft M, Nielsen MD, Lockwood K et al. Urinary excretion of corticosterone metabolites in demonstrating the adrenocortical remnant. Brit J Surg 1974; 61: 955-959

[25] Gotlieb N, Albaz E, Shaashua L et al. Regeneration of functional adrenal tissue following bilateral adrenalectomy. Endocrinology 2017; 159: $248-259$

[26] Speiser PW, Arlt W, Auchus RJ et al. Congenital adrenal hyperplasia due to steroid 21-hydroxylase deficiency: An endocrine society clinical practice guideline. J Clin Endocrinol Metab 2018; 103: 4043-4088

[27] Morris LF, Harris RS, Milton DR et al. Impact and timing of bilateral adrenalectomy for refractory adrenocorticotropic hormone-dependent Cushing's syndrome. Surgery 2013; 154: 1174-1183 discussion 1183-1174

[28] Friedman T. An update on the overnight dexamethasone suppression test for the diagnosis of Cushing's syndrome: Limitations in patients with mild and/or episodic hypercortisolism. Exp Clin Endocrinol Diabetes 2006; 114: 356-360

[29] Friedman T, Ghods D, Shahinian $\mathrm{H}$ et al. High prevalence of normal tests assessing hypercortisolism in subjects with mild and episodic Cushing's syndrome suggests that the paradigm for diagnosis and exclusion of Cushing's syndrome requires multiple testing. Horm Metab Res 2010; 42: 874-881

[30] Mojtahedzadeh M, Shaesteh N, Haykani M et al. Low-dose and standard overnight and low dose-two day dexamethasone suppression tests in patients with mild and/or episodic hypercortisolism. Horm Metab Res 2018; 50: 453-461

[31] Berber E, Tellioglu G, Harvey A et al. Comparison of laparoscopic transabdominal lateral versus posterior retroperitoneal adrenalectomy. Surgery 2009; 146: 621-625 discussion 625-626

[32] Lee CR, Walz MK, Park S et al. A comparative study of the transperitoneal and posterior retroperitoneal approaches for laparoscopic adrenalectomy for adrenal tumors. Ann Surg Oncol 2012; 19: 2629-2634

[33] Esoterix Laboratory Sciences I. Cortisol by HPLC with Mass Spectrometry. 2006, Test \# 803990

[34] Augustine J, Schaffer R, Friedman TC. Successful treatment of adrenal remnant tissue using alcohol ablation in a patient with episodic cushing disease. Endocrine Soc (Abstract) 2011; 93: P2-P650 
[35] Friedman TC, Ghods DE, Shahinian HK et al. High prevalence of normal tests assessing hypercortisolism in subjects with mild and episodic Cushing's syndrome suggests that the paradigm for diagnosis and exclusion of Cushing's syndrome requires multiple testing. Horm Metab Res 2010; 42: 874-881

[36] Sandouk Z, Johnston P, Bunch D et al. Variability of late-night salivary cortisol in Cushing disease: A prospective study. J Clin Endocrinol Metab 2018; 103: 983-990

[37] Petersenn S, Newell-Price J, Findling JW et al. High variability in baseline urinary free cortisol values in patients with Cushing's disease. Clin Endocrinol (Oxf) 2014; 80: 261-269

[38] Findling JW, Doppman JL. Biochemical and radiologic diagnosis of Cushing's syndrome. Endocrinol Metab Clin North Am 1994; 23 : 511-537

[39] Lindsay JR, Nieman LK. Differential diagnosis and imaging in Cushing's syndrome. Endocrinol Metab Clin North Am 2005; 34: 403-421 x

[40] Haioun C, Itti E, Rahmouni A et al. [18F]fluoro-2-deoxy-D-glucose positron emission tomography (FDG-PET) in aggressive lymphoma: An early prognostic tool for predicting patient outcome. Blood 2005; 106: 1376-1381

[41] Wang W, Macapinlac H, Larson SM et al. [18F]-2-fluoro-2-deoxy-Dglucose positron emission tomography localizes residual thyroid cancer in patients with negative diagnostic (131)I whole body scans and elevated serum thyroglobulin levels. J Clin Endocrinol Metab 1999; 84: 2291-2302

[42] Bell J, Brooker G, Harding BW. ACTH activation of glycolysis in the rat adrenal gland. Biochem Biophys Res Commun 1970; 41: 938-943

[43] Crocker MK, Barak S, Millo CM et al. Use of PET/CT with cosyntropin stimulation to identify and localize adrenal rest tissue following adrenalectomy in a woman with congenital adrenal hyperplasia. J Clin Endocrinol Metab 2012; 97: E2084-E2089

[44] Lila AR, Malhotra G, Sarathi V et al. Localization of remnant and ectopic adrenal tissues with cosyntropin-stimulated 18F-FDG-PET/CT in a patient with Nelson syndrome with persistent hypercortisolism. J Clin Endocrinol Metab 2010; 95: 5172-5173

[45] Miles JM, Wahner HW, Carpenter PC et al. Adrenal scintiscanning with NP-59, a new radioiodinated cholesterol agent. Mayo Clin Proc 1979; 54: 321-327

[46] Kazerooni EA, Sisson JC, Shapiro B et al. Diagnostic accuracy and pitfalls of [iodine-131]6-beta-iodomethyl-19-norcholesterol (NP-59) imaging. J Nucl Med 1990; 31: 526-534

[47] Mendichovszky IAPowlson et al. Targeted Molecular Imaging in Adrenal Disease-An Emerging Role for Metomidate PET-CT. Diagnostics (Basel) 2016; 6: 42

[48] Wannachalee T, Turcu AF, Bancos I et al. The clinical impact of [(68) Ga]-DOTATATE PET/CT for the diagnosis and management of ectopic adrenocorticotropic hormone - secreting tumours. Clin Endocrinol (Oxf) 2019; 91: 288-294
[49] Redvanly RD, Chezmar JL, Strauss RM et al. Malignant hepatic tumors: Safety of high-dose percutaneous ethanol ablation therapy. Radiology 1993; 188: 283-285

[50] Shiina S, Tagawa K, Unuma T et al. Percutaneous ethanol injection therapy for hepatocellular carcinoma. A histopathologic study. Cancer 1991; 68: 1524-1530

[51] Curley SA, Izzo F, Delrio P et al. Radiofrequency ablation of unresectable primary and metastatic hepatic malignancies: Results in 123 patients. Ann Surg 1999; 230: 1-8

[52] Demolin JM, Eick O], Münch K et al. Soft thrombus formation in radiofrequency catheter ablation. Pacing Clin Electrophysiol 2002; 25: 1219-1222

[53] Martirossian A, Jacob R, Riley K et al. A novel approach to ectopic adrenal tissue in Nelson's Syndrome Endocrine Soc 101: MON-416 (Abstract) 2019

[54] Castinetti F, Guignat L, Giraud P et al. Ketoconazole in Cushing's disease: Is it worth a try? J Clin Endocrinol Metab 2014; 99: 16231630

[55] Cook DM, Loriaux DL. Cushing's: Medical approach. Curr Ther Endocrinol Metab 1997; 6: 59-62

[56] Loose DS, Kan PB, Hirst MA et al. Ketoconazole blocks adrenal steroidogenesis by inhibiting cytochrome P450-dependent enzymes. J Clin Invest 1983; 71: 1495-1499

[57] Duret C, Daujat-Chavanieu M, Pascussi JM et al. Ketoconazole and miconazole are antagonists of the human glucocorticoid receptor: consequences on the expression and function of the constitutive androstane receptor and the pregnane $\mathrm{X}$ receptor. Mol Pharmacol 2006; 70: 329-339

[58] Loose DS, Stover EP, Feldman D. Ketoconazole binds to glucocorticoid receptors and exhibits glucocorticoid antagonist activity in cultured cells. J Clin Invest 1983; 72: 404-408

[59] McCance DR, Hadden DR, Kennedy L et al. Clinical experience with ketoconazole as a therapy for patients with Cushing's syndrome. Clin Endocrinol (Oxf) 1987; 27: 593-599

[60] Kannan CR. The Adrenal Gland. New York: Plenum Medical Book Co. 1988

[61] Allolio B, Hahner S, Weismann D et al. Management of adrenocortical carcinoma. Clin Endocrinol (Oxf) 2004; 60: 273-287

[62] Baudry C, Coste J, Bou Khalil R et al. Efficiency and tolerance of mitotane in Cushing's disease in 76 patients from a single center. Eur J Endocrinol 2012; 167: 473-481

[63] ] Cushing's Syndrome Redux. Endocrine News: Puzzler Page Sept 2011 